\title{
Challenges Faced Muslim Women Leaders in Higher Education
}

Samah Hatem Almaki

almakisamah@gmail.com

\author{
Prof. Dr. Abu Daud Silong
}

abudaud.silong@gmail.com

\author{
Prof. Dr. Khairuddin Idris
}

Dr. Nor Wahiza Abd. Wahat

Department of Professional Development and Continuing Education

Faculty of Educational Studies, Universiti Putra Malaysia

Doi:10.5901/jesr.2016.v6n3p75

\begin{abstract}
The role of Muslim women in the society has changed dramatically in the last 20 years. As a result of the increasing prevalence of women at all levels of education and in different fields of employment and aspects of public life, women now seek to achieve the highest leadership roles in all sectors and as well as in higher education sector and to participate on the various positions and in the decision-making process in public and private sectors. However, women who strive to assume the leadership positions are facing multiple challenges and many times give up because they become overwhelmed in dealing with multiple barriers. Therefore, the objective of this qualitative, phenomenological article is to probe into challenges that Muslim women academic leaders face both in their leadership position and in their communities by using semi- structured interview with some Muslim women academic leader. It is ascertained through the study that Muslim women academic leaders find it hard to make a significant impact in terms of knowledge due to the attitude of society toward women leaders and many women feel that society is still male dominated, and men are not accepted the idea of women holding senior posts, as well as personal and organization challenges. At the end, the article recommends different strategies to overcome these challenges and develop women in the position of leadership.
\end{abstract}

Keywords: Multiple Challenges, academic leadership, Malaysian women leaders, Saudi women leaders.

\section{Introduction}

One the most considerable topics of discussion across most fields is women leadership. This topic attracting researchers' attention for many years, it is becoming increasingly difficult to ignore the limited of opportunities and leadership roles for women in higher education (Madsen, Longman, \& Daniels, 2012). This growing interest is triggered by the importance of leadership as an essential element to the survival of organizations and as an instrumental factor in their strife for excellence (Stead \& Elliot 2009). This interest is also influenced by the increasing role that women play in organizations (Al Ahmad, 2011). Muslim women are a diverse community, coming from many different ethnic, cultural, and linguistic backgrounds, not to mention having different levels of religiosity. Islam recognizes equality between men and women regarding their physical, spiritual and intellectual potential as propounded in the Quran that,

'O people! Be careful of your duty to your lord, who created you from a single soul and created its mate of the same and spread from these two a multitude of men and women' (sūrat I-nisāa, 4:1).

Nevertheless, in spite of this fungal equality, women in most Muslim societies have often experienced marginalization and discrimination, with serious implications for equal opportunities in all sectors of life including education and leadership (Shah, 2012). Indeed today, women comprise the majority of university and college enrollments, but the gaps still exist in educational participation for women. Meanwhile, gender differences topic continues to receive attention among practitioners and researchers in education and human resource development. This is due to 
the fact that although the participation trend has changed in favour of women, particularly, in many developed countries, there still remains the question of whether a similar trend persists in developing nations (Ahmad, 2009). Although, women have proofed to be more committed to their work tasks than men and it was often quoted by society that women are capable to do a man's job, but men are not able to take the responsibility held by women Kwah, Kow, Lee, Lee, \& Lim, (2012) Although academia is a fertile ground for women to develop their career, striving towards academic excellence is not a plain sailing. It is full of excitement, challenges and hurdles before they can reach the highest echelon in academia, i.e. the professoriate (Ismail \& Rasdi, 2007).

It can be argued that Muslim women leaders in higher education are still harshly underrepresented as leaders in Muslim society. Thus, the purpose of this paper is to explore the challenges that faced Muslim women academic leaders in Muslim societies on the advancement to top of the leadership positions in higher education and illustrate the prospects and possible solutions which help to promote Muslim women's academic leader participation at this level.

\section{Literature Review}

\subsection{The status of Malaysian and Saudi Women leader in Higher Education}

Nowadays, Malaysian women are important contributors to the country's social and economic development. As much advance has been attained in the past few decades in narrowing the gender gap in Malaysia, as is obvious in the development in women's roles, both in relative and absolute terms, in the major socioeconomic aspect of the country's development: growing rates of women's manpower participating, gains in the productive activities of women and their strengthened economic standing, there increased involvement in education, as well as their improved health status (Hashim, 2008). In academic field, the percentage of women has increased gradually in the total population over time. In 1980, women comprised 31.7 percent of people with higher education. The number increased to 40.6 per cent in 1991 and further increased to 47.5 percent in 2000 . Women enrollment at all levels of higher education increased significantly between 1985 and 2008. Have women exceeded men at all levels of higher education. Statistics demonstrate that in 2008, women represented 57.2 percent of all graduates from higher education institutions. In the public higher education institutions their share is 62.7 per cent of graduates, whereas in private institutions their share is 56.5 per cent (Yusof, Alias \& Habil, 2012). In addition, the number of women PhD holders within the academic ranks at universities is a crucial index as it means the presence of senior, well-established women who are likely and capable of achieving a leadership position within their institutions, and this includes the positions of deans, heads of departments, and Vice-Chancellors. However, four women have been assigned to the post of Vice-Chancellors in public universities in Malaysia. Moreover, women account for less than forty percent of all PhD holders in Malaysian in higher education today may prove to be an obstacle whether women are to be encouraged to obtain leadership positions (Ali, 2012).

The state of Saudi women not far from the Malaysian women, Saudi Arabia has witnessed major changes during the past few decades, with women taking more responsibility in public spheres and occupying higher positions in organizations, Human Rights Watch (2010) report that in Saudi Arabia some progress is being made in lifting some restrictions on women since 2005 by King Abdullah bin Abd al-'Aziz Al Saud. In June 2004, the third Saudi national dialogue addressed women's rights and duties in Saudi society (Le Renard, 2008). In this cycle of the Saudi government holding many national dialogues, the dialogue included discussions regarding women's rights and responsibilities, women and work, women and education, and women and society (Le Renard, 2008). Parveen (2014) captured the most recent progress in Saudi women's career advancement in which they have demonstrated their ability to uphold leadership positions in private and public sectors. For instance, in 2009, Nora bint Abdullah al-Fayez was appointed the First Female Saudi Arabian Minister (Alexander, 2011). Princess Jawhara Fahd bin Abdulaziz, got the rank of minister, when she was appointed leader of the Riyadh University for Girls formerly "University of Princess Noura Bint Abdulrahman" to be the first Saudi women get this position and place (Alexander, 2011). After that Noura al-Fayez got the first position leadership in the Ministry of Education five years ago as Deputy Minister of Education. Also, Dr. Mounira Maaloul won post of deputy governor for technical training for girls in the General Organization for Technical and Vocational as the first Saudi training you get the job. In addition, Dr. Haya Awwad got in the position of Undersecretary of the Ministry on the fifteenth ranked as the first citizen to hold this position in the history of ministries (Al-Ghamdi, 2013).

\subsection{Challenge to Muslim Women's Academic Leaders Progression}

Women academicians in leadership positions encounter numerous challenges to their progress both personally and 
professionally. Challenges may be internally created by the individual herself or may be generated by external challenges that may come from society in general or the institutional practices in place (Drury, 2010). This section of the study reviews the literature on challenges facing women leaders in general and in Malaysia, in particular. There are similarities that women face all around the world, but the unique culture in the Malaysia region poses a different set of challenges. The lack of women in senior positions in itself acts as a barrier to more women reaching higher levels within institutions.

\subsubsection{Social Attitude of Women as a Leaders}

One of the typical barriers for women moving up to senior management position that was highlighted by Oakley (2000) and Ozkanli \& White (2008) were gender-based stereotypes. Specifically, Bilen-Green, Froelich \& Jacobson (2008) have mentioned that in the case of women's less than full participation in higher education for several decades, there is a range of behaviors that does not support the women such as, stereotyping, and support rather than leadership roles that discourage and disadvantage women at all levels in academia. A number of prevailing beliefs and cultural concepts and concerning the view of women as leaders, whether in the eyes of her subordinates, her men colleagues, or women colleagues as well (Al-Jaradat, 2014). Similary, Al Shihabi, Azzam \&Abdul Majid (2003) describe the negative perception of the official leadership for women, negative outlook of the community toward women's work, and gender discrimination in the occupation of leadership positions. And undoubtedly that view of male towards women and men's antipathy to hiring women impedes the advancement of women leadership position (Billing, 2011). In addition, Tomàs, Lavie, del Mar Duran, \& Guillamon, 2010) indicted that one reason for the inequity within organizations is that many male leaders hold a certain perspective about women's role as leaders. These men assume that women succeed in leadership positions only when they behave and hold male characteristics such assumptions force women to assimilate as men in order to be taken seriously and to succeed professionally. In the study of (Black, 2002); (Elmuti, Jia, \& Davis, 2009); and (Burns \& Martin, 2010) showed that women's leadership is facing the challenges of respect and poor confidence as compared by that of the man's leadership.

\subsubsection{Organization Challenges}

In addition, women have not attained leadership positions in any significant numbers due to some factors, such as lack of acceptance of women as leaders, culture, overall changes in the workplace, women's ways of communicating in the workplace, and generational change, also need debate and discussion. Organizational and administrative challenges also contribute in interception the march of women to take up senior positions, these barriers may vary according to the institution and the system (Still, 2006). Simillary, Al-Qahtani (2006) found that women have influenced by several challenges such as financial allocations for creativity, shortcomings in organizations Higher education in terms of stimulus policies, and training and education policies in the field of creativity. Ozkanli \& White (2008) indicted to other factors that hinder women from the top are due to cultural adaptation, low morale, promotion, lack of training in management roles also standing in the way of women to access leadership position. Moreover, Melamed (1995) stated that the challenges to advancement for women in were: exclusion from networks, lack of experience. Additionally, Sadi \& Al-Ghazali (2010) indicated that Saudi business women face additional barriers related to institutional policies and culture. These are: lack of coordination between the various governmental departments, lack of protective laws, lack of governmental policies, and cultural and social restrictions. The study of Al-Halawani (2002) \& Almenkash, Abdulaziz, Shaman, Haijan \& Dagsh (2007) found that lack of centralization of authority and authority in headquarters run by men restrict women's ability to make decisions and to lead effectively. Furthermore, Al-kayed (2015) found that Saudi female managers face a number of challenges, the most important challenge is dealing with different natures of subordinates, the long working hours, and lack of authorization.

\subsubsection{Personal Challenges}

Several factors associated with the personality of women leaders and their social circumstances, may hinder their ability to fully exercise their leadership role effectively. Family related barriers also play a pivotal role in preventing women's to access the top of leadership position. The traditional division of labour leads people to expect domestic responsibilities to be women's primary roles and any obligation that detracts from their ability to perform their primary role causes role conflict. In the view of most employers and many employees, the gender division of labour frees men from domestic and childcare responsibilities at home (Charles \& Aull Davies, 2000). The work and life balance is a barrier to almost all 
women even though to unmarried and single women (Mooney \& Ryan, 2009).

Research OF Neale \& Ozkanli (2010) has shown that women, particularly those in traditional societies, are expected to take more family responsibilities than men, such as solely careering for their children, husband, and extended family. They are also required to do more domestic work. Such role expectations have been found to be an important obstacle in the academic career progression of women in Turkey. Similarly, Tomas, Lavie, Duran, \& Guillamon (2010) indicate that there are numerous factors that may be at play in preserving the inequality between men and women who occupy leadership positions in higher education. Family and personal obligations may be one of the most prominent reasons for excluding women from managerial positions in higher education. Ellison (2006) proposes number of strategies which help women in balancing the many demands of life including prioritization, time management, networking with other women, dealing with difficult situations, focus on the future, and handling chaos.

\section{Methodology}

A phenomenology case study used in this study which will allow the researcher to analyze within each setting and across settings. In a multiple case study, we are examining several cases to understand the similarities and differences between the cases. Yin (2003) explained how multiple case studies can be used to either, "(a) predict contrasting results but for predictable reasons (a theoretical replication) or (b) predicts similar results (a literal replication)" (p. 47). The study employed an in-depth personal interviews method to qualitative research in order to gain an in-depth understanding of the challenges faced Muslim women's leadership in higher education. The Muslim women came from diverse disciplines within two Universities which are University Putra Malaysia and (UPM), and King Abdul-Aziz University in Saudi Arabia and they held senior leadership positions (e.g. Head of Department and Vice- Dean). Data were generated through semistructured interviews of approximately 60 minutes in duration that were digitally recorded, transcribed by the researchers to ensure accuracy and affirm meaning. Through a process of thematic analysis (Braun \& Clarke, 2013), emerging groups of data and observations of similarities and differences of meanings were explored.

\section{Findings and Discussion}

In this section, we present the findings of the study organized by two major aspects, beginning first with findings pertaining to the experience of challenges that face Muslim women academic leaders. These findings are discussed in terms of key themes that we identified through the analysis. Three broad themes emerged from the analysis of the interviews which are relevant to the challenges influence Muslim women leaders' career in higher education are divided into: Social Attitudes and confidence, organizational and individual challenges. Categories were further extracted from description of related data.

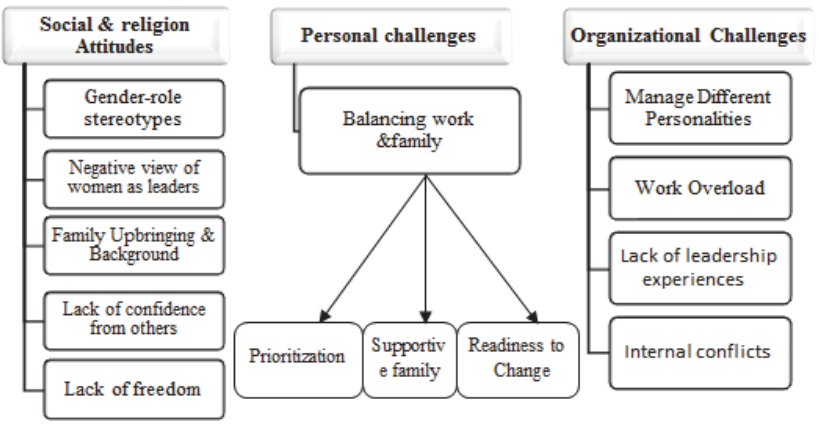

Figure 1: Themes and sub categories

\subsection{Social \& Religion Attitudes}

Societal factored are the most difficult and time-taking factors to change as they have an effect on various dimensions of life and cannot be easily controlled. Participants in Malaysia and Saudi Arabia acknowledged that society challenges play a significant role to stand in the way of women's progress to senior positions within their university. Muslim women are 
required to follow particular cultural traditions imposed by the society in which they live. This finding also supported by (Al Shihabi, Azzam \&Abdul Majid, 2003), (Oplatka, 2006), and (Luke, 2000).

According to the finding of the study, various factors in society attitude influence women leaders in their leadership journey which are:

\subsubsection{Gender-Role Stereotypes}

Stereotypes and prejudice still affect women's career development strongly (Oakley, 2000; Bilen-Green, Froelich \& Jacobson, 2008). The differences between women and men in their behaviors are a result of the different roles the two genders play according to the expectations held by their society. Abilities, which people expect a leader to possess, are more closely associated with the male gender stereotypical characteristics than the female gender stereotypical characteristics. Four participant in both case study were indicated at that gender-role stereotypes create impediments for Muslim woman leader in terms of access to a leadership position in higher. The participants pointed out that the expected social roles and gender stereotypes when they interacted with men was that men were viewed as leaders. Nai explained that:

"..Society is a masculine society. Because of culture and the approach of choice. But I can't deny that a lot of colleges have women in higher authority like dean, the ratio is very weak."(Nai)

According to the Muslim women in both countries, woman leaders were more emotionally affected in their work, and that was not very good for leadership. Nob stated:

"Women have always stereotyping, like always emotional, but if you are emotional when you hear bad news, you have to pick up yourself very quickly, and you have to show that I am an authority."(Nob)

\subsubsection{Negative View of Women as Leaders}

In the past, research has reported that the view of male towards women is a major obstacle to female entrance in leadership position (Phendla, 2009). Al-Hussein (2011), (Billing, 2011), and Al Shihabi, Azzam \&Abdul Majid (2003). Number of prevailing cultural concepts and beliefs concerning the view of women as leaders, whether in the eyes of her men colleagues, her subordinates or women colleagues as well. Malaysian participants strongly mentioned that the society hold certain attitudes towards women as leaders. Firstly, men attitude for women, The Malaysian women leaders expressed their dissatisfaction with the negative perception of the man leader and try to disparage their possibilities and capabilities. These men assume that women succeed in leadership positions only when they behave and hold male characteristics. Nob indicated about this challenge by saying:

"Some of the male lecturers especially the senior. They will try to put you down in the meeting....I think this very important that you don't let yourself be trampled by the male or non-Muslim."(Nob)

On the contrary, Saudi women leaders have different perspective about the perception of society and male. Four participants confirmed that the view of women in Saudi culture and men has changed, society has become more open than before. It's becoming more appreciation and respectful, and estimated for her role of women in the society. Participants give the reasons of the change of the view for women in their society, because of women prove their ability and they put their finger in the achievement of their university. They said that they are proud of what Saudi women has reached in leadership position. Abe said:

"If you want to talk about Saudi Arabia, the view for women has changed and the society has become more open. Many people travel abroad and many people from other countries come to Saudi, also the mission for students was from many years ago not new."(Abe)

DAW was proud of what women in Saudi Arabia arrived from leadership positions and its ability to prove her effectiveness in holding leadership positions in higher education by saying that:

"If we talked about Saudi Arabia, in particularly, King Abdul-Aziz University, we are proud of what Saudi women has reached in leadership and left her finger and still. Women are respected in all sectors. Society's perception, women still get many entitlements."(Daw) 
The second perception for women leaders highlighted by Muslim women leaders was attitude of religion for women as a leader. Two participant from Malaysia believe that men and women are seen as having different roles in religion and daily life. So they should have different rights in leadership position. In the Islam the Kalifa is man so often leader should be man, and the Islam give men more probate than women, therefore, woman should have confidence and accepted with this situation. Mai said:

"Leaders must be man related by Allah, That's why I have given that $20 \%$ to $40 \%$ presently. Man get in terms of probate more than women, so that is references already when men are given more probate, so perception or society man must also lead, is an it.(Mai)

On the contrary, one of the participants also from Malaysia believes reverse this opinion, she think that Islam honored woman and men and women are completely equal in religion and given her the opportunity to be knowledgeable, but misunderstanding of the teachings of the Islamic is one of the reasons for gender role in society:

"I think not because of religion or society, it's because of the way of your thinking. It happened not to understand Islamic or Quran or Hadith say that way, because beyond that actually in our religion there is saying clearly that woman and man are given the opportunity to be knowledgeable, you can learn as much as you can, to be a good Muslim as much as you can, but don't misinterpreted, when you misinterpreted it make your live difficult."(Wan)

\subsubsection{Family Upbringing \& Background}

Family upbringing for men and women often involved determining the effectiveness of women to occupy leadership positions and in the participation in decision-making - whether the decision was an administrative, social, or political decision and mainly men were responsible for making and implementation this decision (Bornstein, 2007; Tomas, Lavie, Duran, \& Guillamon; 2010) The familial impact appeared as a key factor in life choices on work and family for all Muslim women leaders. The influence of familial on thinking of children about holding women leadership position and their role in workplace, they confirmed that family upbringing contribute to push women to reach the upper ranks. Perhaps, the Muslim women leaders themselves have internalized a sense of gender neutrality at work as a result of the deeply rooted social expectation of their family roles. This finding indicate that Muslim academic women's in Malaysia slow professional progress is mainly due to the social expectations of their role in the family and their role in the future. Int stated:

"I see my mam she was a strong women. so, she didn't have high education, but the way she carry itself, and the way to brought me up, of course she punch me, but she also all the time she will be saying that, she will be successful, you are clever enough, you good, you will be somewhere in the future, so because of that you built in yourself that I am good, I will be somewhere one day. That positive input always people being saying to you."(Int)

\subsubsection{Lack of Confidence from Others}

Many researches indicated to the attitudes about the role of women and their abilities to lead such as (Burns \& Martin, 2010); (Black, 2002); (Elmuti, Jia, \& Davis, 2009); and (Keohane, 2014). Two Malaysian participants and one from Saudi highlighted a lack of confidence from society to women is a problem for women to be in leadership position. Such attitudes portray woman being physiologically and intellectually inferior to men, tough, inflexible, don't have the capacity to think, don't have the experience to make a good decision, and naturally sensitive and emotional. Therefore, they cannot be able to be a leader. Mai stated:

"Society's perception saying that the women not suitable, especially when you are at home your husband when let you go very much higher, ok. That is in the family; one more if you go outside the family's atmosphere the same perception is there."(Mai)

Nai Saudi women leader shared the same point of view:

"Community culture is masculine because they see that woman are tough, inflexible and should be going in a certain way. But men can easily doing things."(Nai) 


\subsubsection{Lack of Freedom}

In Muslim society women are required to obtain permission of father, husband, or other male guardian. Freedom key demand whether in the family or in the workplace. Three of participants in both countries of Malaysia and Saudi Arabia described to two types of lack of freedoms that they faced in their live. The first type is the lack of family freedom in the sense that leadership position needs to participate in a lot of activities and sometimes do not get permission from her husband to participate in these activities which is consider as an obstacle for women in leadership position. The other type is lack of freedom in decision-making in their post, they must-have recourse to higher authority so they can make academic decision. Mai from Malaysia said:

"More challenge to woman if you have to go somewhere else like for a professional activity somewhere, you need to get some permission, if your husband says no, you can't go."(Ma2)

Other type was organizational structure in the university which related to decision making. Saudi women leaders have this type of challenge related to lack of freedom in making decision without reference to any men's section. They have mentioned that women leaders in university must refer to the dean in the men's department to make a financial and material decision. The current study's result are supported by Al-Halawani (2002) and Almenkash, Abdulaziz, Shaman, Haijan \& Dagsh (2007). Nai summarized her opinion by saying:

"..The challenges we faced as management is we don't have full freedom. There is a bureaucracy. Sometime we have to get approval from higher authorities or higher authority. I have to go according to hierarchy, I have to go to the top of hierarchy at the university which is man and ask them the agreement."(Nai)

\subsection{Personal Challenges}

\subsubsection{Balancing Work \&Family}

Muslim women struggle with work/life balance. Muslim women leaders still have strong traditional social expectations, and not all women can easily juggle both a professional career and family obligations. Interviews revealed that the work life balance of women was one of the challenges faced by Muslim Malaysian and Saudi women in leadership positions in higher education. This finding is unsurprising as work/home tension is a barrier to women elsewhere in the world (Mooney \& Ryan, 2009). (Vinnicombe \& Singh, 2011), (Alomair, 2015)), and (Nguyen, 2013). Numbers of Muslim women are struggling to accommodate the demands of work and family life. In finding Muslim women leaders give simple ways to improve your Work-Life Balance:

\subsubsection{Prioritization}

One of the best ways to practice leadership is to recognize the role of work and home. At the same time, it's important to prioritize the work and family so that can achieve the balance as smoothly and efficiently. This result support by Ellison (2006) and Friedman \& Greenhaus (2000) who alluded that when family and work were integrated, the two roles could enhance each other by managing their role. According to three of participants from both countries knowing the priorities was one of the ways to achieve a balance between family and leadership position. Women described the way to achieve the priority by understanding their roles, give both side of work and family the scenario of their role, manage home and manage office, management their time. Nob indicated that prioritizing helped her to achieve her goals:

"I have priorities, but in order for me to let other people - whoever is my superior- understand, I have to give them the scenario, and I told the dean my senior. So the same with the family, I will tell them the scenario at work, what is expected of me that sometimes I can't be home with them because I have to go for training and course and things like that".(Nob)

\subsubsection{Supportive Family}

Across the board, Muslim women academic leaders insisted that managing family and professional life requires a strong support from the family. In finding not surprisingly that family support is the strongest facilitator for the Muslim women leaders not only prior to but also during their working. This finding support from study of (Cheung \& Halpern, 2010) and 
Cubillo \& Brown's (2003). Three participant in both cases stated that being supported husband, parents and family make their live easier and most of these women leaders confirmed that she could not access the leadership position without the support of their husband and parents. Sit thanks her God that he gives her understanding and supportive husband, she said:

"I am very grateful to Allah that I have very understanding husband. For my career he has been very supportive."(Sit)

Waf used democratic way to get support from her husband and boss by explaining the scenario for both parties to get the support from her husband and manager. She was happy as her husband was very understanding:

"Before I agreed to take this position I asked my husband and I told him the scenario maybe they asked me to travel or I will be late to attend meeting. On other hand I told the dean if you want me to travel, I have to ask my husband first. My husband very understand person because he works as Chancellor and he knows already what this position require."(Waf)

\subsubsection{Readiness to Change}

Another solution were given by Muslim Women leaders to achieve the balance between home and work is change the situation to be more flexible. Among the challenges the leader (both male and women) faces in education institutions, is the ability to employ the legal and personal power in the strategic leadership, innovation and ability to change, flexibility at work (Al-Jaradat, 2014). Two women leaders in Malaysia mentioned that women can achieve the balance between the work and family when they let other understand the natural of their work, and change the way that they act in their home and in their work, women should know how to separate between their work and their family by giving each of them enough time. Int said:

"You have to understand, you have you change your position, you have to change the way that you act, if you acting like this, if you go home you have to change your act, you can't be a boss always." (Int)

\subsection{Organizational Challenges}

As noted in researches cited earlier in this article, such as, (Al-Qahtani, 2008), (Still, 2006), and (Al-Zuhair and Allaithi, 2010) organization and administrative are often among the major challenges for Muslim women professionals. The results of this study also showed that Muslim women academic leaders in Malaysia face organization challenges, maybe the qualities are different but it is still linked to administrative work. The interviewee added some of the challenges that they face during their career that relate to the administration work. Mai said:

\subsubsection{Manage Different Personalities}

This view finds support in the study conducted by Al-kayed (2015) which results pointed out to that female managers face a number of challenges, the most important challenge is dealing with different natures of subordinates, the long working hours, Two participants from two countries have the same opinion and they described how their challenge had caused connections to others, trying to get cooperation with faculties, and understanding from different level of people in different departments, also get the cooperation from different department and stuff are a big challenge for them, Nob Malaysian leader stated:

"One of the challenges of being a woman leader in academic position is that a lot of a work that sometimes you have to deal ,you deal with male colleagues, you deal with the head of the department who are male, some of them a professor, and non-Muslim. So I think what you need to know is, I wouldn't be saying manage them, but understanding them, also it's difficult to get the cooperation from the different department, from the staff member, from the support staff. I think that is the biggest challenges because it's not about popularity contests" (Nob)

Another woman leader from Malaysia commented that:

"Trying to deal with different level of people, from the different department, from the staff member, from the staff. I think that is the biggest challenges."(Abe) 


\subsubsection{Work Overload}

Large number of workloads another challenge faced Muslim women leaders in higher education. This view finds support in the study conducted by Al-kayed (2015) which results pointed out to that female manager's face a number of challenges, the most important challenge is the long working hours. Participants had the same opinion concerning the increased the dual burden for Muslim women academic leaders. They commented that she has to manage many thing in her work and family so it is a great burden on her may make a lot of women do not want to assume this responsibility, which is a burden on women in their live. This is exactly what has been emphasized by $\mathrm{Nai}$

"One of the challenges that I faced is that all the programs such as (Distance education- program of affiliation- the programs special for masters - the Bachelor) all this constitutes a burden for me."(Nai)

\subsubsection{Lack of leadership experiences}

One of the biggest challenges face Muslim women leaders in Saudi Arabia in their career paths is having "enough" experience (Melamed, 1995) \& (Ozkanli \& White, 2008). Participant mentioned that the converting women academic from academic work to administrative work without training or "enough "experience in leadership administration work is a big challenge of them in leadership position especially when the need to make quickly decision. They suggested various way to integration academics in administrative work by giving them time and training to be familiar with the administration tasks. Abe Saudi women leader said:

"There are many problems for me, the most thing that I see that a person suddenly transfer from a purely academic to an administrative work, for example, they give the leaders two weeks or one month at least to get familiar with the situation, give the leader something like training. It is not training in the true sense, but make person know how to deal with transactions, how can reply it, what the things that can reply on it and what it shouldn't reply."(Abe)

\subsubsection{Internal conflicts}

The position held by women in leadership positions impose a set of responsibilities and duties that make women more vulnerable than others to a range of pressures, resulting from the multiplicity of roles played by women. Conflict of values and interests in the institutions in which it operates one of the challenges facing the Muslim women leaders in Saudi as well as in Malaysia. Waf reflected on her experiences:

"One of these problems is conflict between staff and administration staff in management, this effect on the effectiveness of organization. Also, motivation problems, there aren't criteria of motivation, these cause grudge between staff about chosen the person..."(Waf)

\subsection{Strategy to Overcome Challenges}

Muslim women academic leaders often have life skills and natural abilities that are useful in their career and can overcome the challenges that they faced and assume senior position. Despite all the challenges related to social, religion and organization that Malaysian women were faced in their workplace, Participants provided tips to overcome these challenges and will support women who are seeking leadership positions as follow:

1. Leadership development programs: the first suggestions made by all participants is to provide training programs related to the development of women leadership skills that these programs be more practical than theoretical such as: programs to educate the society, dealing with the problems staff. dealing with problems, making a decision, how to be psychologically stable, handle the situation, Administrative program for develop skills of technicians, reports, and writings, develop procedure way and programs for initialization and attract leaders. Moreover, two of the participants stressed the importance of including moral and religious aspects of the Islamic at all of these programs.

2. The Acquisition of Knowledge

a. Learning: The basis of development in any sectors is education. Participants stressed the importance of education and learning for women to lead effectively as well as to send positive messages about the value of Muslim women and the real contributions on their communities. In the opinion of the participants, particularly Malaysian women, education is very important for women includes a multi- aspects which are 
first self -educate by looking for different material to know their roles and their work as well as keep up with evolution in their field. Moreover, they strongly confirmed to educate the society -men and womenabout the role of women as a leader to give women chances and opportunity if they have the talents and resources.

b. Awareness: Malaysian participants provided another strategy to overcome the challenges facing women through promoting community awareness and changing the direction of thinking about women by instilling values and Positive concepts about the upbringing of women and their role in the social and practical of life and definition Men and women of their rights, duties and roles in life. On the other hand, women should have a knowledge and understanding of the current higher education environment and the role of the women leaders in their live.

c. Demonstrate ability: Five participants agree with the same strategy which helps women to face their challenges which is build their self-confidence by self-confidence, established a good relationship based on communicate and mutual respect between them and others, showing their authority, controlling their emotions. One of the Saudi participants strongly affirmed that when woman leader has a clear vision, know their role, know what you want from themselves and from others, she can easily prove itself as an effective leader.

\section{Conclusion}

The world witnessed several Muslim female leaders who effectively flourished their viewpoints globally, but there is an immense shortage for women academic leader as compared to the male in higher education sector. The primary objective of the article was to capture the experiences of Muslim women leaders and to highlight the challenges encountered by them in order to pave the way for future generations of aspiring women to assume leadership position using University of Putra Malaysia and King Abdul-AL Aziz University in Saudi Arabia as cases of studies.

In the light of the study findings, it can be concluded that while Muslim women academic leaders have the ability and potential to be effective leaders to perform at the top level of leadership position, the vicious cycle of challenges against their leadership path often hinder their success. Attitudes of society and cultural stereotypes, attitude of male and religion for women as a leader, personality factor, which is found to be incongruous for an academic leader such as the problem of balancing work. As well as, organization factors that have a direct relation to their work such as, dealing with different personalities, work overload, lack of leadership experiences and internal conflicts were the main challenges faced both cases in their working and family which retards their influence in the fields of academics

This findings calls for the need to take suitable developmental procedures by the education policy in the area, to encourage the leading role of the Muslim woman in the educational institutions and their various levels. This could be achieved through several strategies that Muslim women leaders should follow to sustain overcome these challenges such as availing opportunities before the leaderships to join training courses in the field of leadership, acquisition of knowledge, and demonstrate their ability as a successful Muslim women leaders.

The researcher suggest the following actions:

- There is a need in society towards a paradigm shift towards women's capability to lead and give her the opportunity to prove herself to contribute in the development of the organization for the better.

- Muslim women academic leaders should be allowed to influence communities they work in just like their male counter parts or even better,

- Support women psychologically, socially and politically, create the suitable conditions to show their capabilities and efficiency.

- Try to modify the image of women in front of themselves, and make them aware of their rights and their role in overall development, and capabilities that can convince her of her performance in which the leading role by highlighting the successful experiences of women's administrative leaders In different locations in the Arab and Muslim world.

\section{References}

Ahmad, A. (2009). Gender differences and trends in the participation of Malaysians in education: Implications on employment outcomes. Journal of International Management Studies, 4(2), 65-74.

Al Qahtani,M.A.(2006).The effective factors of administrative female leadership innovative management behavior astudy on higher 
education organization in Makah's district g Master Thesis, King Abdul-Aziz University, Jeddah.

Al-Ahmadi, H. (2011). Challenges facing women leaders in Saudi Arabia. Human Resource Development International, 14(2), 149-166.

Alexander-Snow, M. (2010). Women at the Top: What Women University and College Presidents Say about Effective Leadership (review). The Journal of Higher Education, 81(6), 779-782.

Al-Ghamdi, F. S. (2013). The Obstacles that Stan Against Saudi Women to Reach Leadership Position in the Public Sector; A field study of Female Employees at King Abdul- Aziz University- Jeddah. Master theses of Sociology, Faculty of Arts and Humanities.

Al-Halawani, I. (2002). The obstacles that stand in the way of working women and impede the progress of success. Arab Journal of Management, 22(2), 61-120.

Al-Hussein, E. B. (2011). Traits and skills characterizing the Jordanian leader woman and obstacles facing her. Damascus University Journal, 27(3, 4).

Ali, T. E. (2012). Women in Leadership Role in Academia and Education: Enhancing Malaysian Female Participation, High-Level International Roundtable for Women in Leadership Roles in Science and Technology - "Getting There" 4-5 September 2012 Swiss Garden Kuala Lumpur.

Al-Jaradat, M. K. M. (2014). Challenges Facing Women Academic Leadership in Secondary Schools of Irbid Educational Area. International Education Studies, 7(5), p147.

Al-kayed, L. (2015). Leadership Challenges for Women Managers in Public Universities in Saudi Arabia. Global Journal of HumanSocial Science Research, 15(4).

Almenkash, S., Abdulaziz, M., Shaman, A., Haijan, A., \& Dagsh, N. (2007). The issue of management women/men in higher education institutions for girls, the draft plan for the future of higher education in the kingdom of Saudi Arabia. Al-Riyadh: King Abdullah Institute for Research Consultancy Studies.

Alomair, M. O. (2015). Female Leadership Capacity and Effectiveness: A Critical Analysis of the Literature on Higher Education in Saudi Arabia. International Journal of Higher Education, 4(4), p81.

Al-Shihabi, Inaam, Azzam, \& Abdul Majid. (2003). Directions of Jordanian women's leadership in Jordan shoved constraints and women's access to senior leadership positions. Jordan Journal of Applied Sciences, 6, 96-114.

Al-Zuhairi, I., \& Al-Laithi, R. (2010). The educational management and school management in the twenty-first century (1st ed.). Hael, Kingdom of Saudi Arabia: Al-Andalus Publishing and Distribution House.

Bilen-Green, C., Froelich, K. A., \& Jacobson, S. W. (2008). The prevalence of women in academic leadership positions, and potential impact on prevalence of women in the professorial ranks. Women in Engineering ProActive Network.

Billing, Y. D. (2011). "Are Women in Management Victims of the Phantom of the Male Norm?" Gender, Work \& Organization 18(3):298317.

Black, L. J. (2002). Personal and Professional Challenges Faced by Women who are Administrators in Higher Education .A Dissertation Presented to the Faculty of The Graduate School of Education and Psychology Pepperdine University.

Bornstein, R. (2007). Why Women Make Good College Presidents.Presidency, 10(2), 20-23.

Braun, V., \& Clarke, V. (2013). Successful qualitative research: A practical guide for beginners. Sage.

Burns, G., \& Martin, B. N. (2010). Examination of the Effectiveness of Male and Female Educational Leaders Who Made Use of the Invitational Leadership Style of Leadership. Journal of Invitational Theory and Practice, 16, 30-56.

Charles, N., \& Aull Davies, C. (2000). Cultural stereotypes and the gendering of senior management. The Sociological Review, 48(4), 544-567.

Cheung, F. M., \& Halpern, D. F. (2010). Women at the top: powerful leaders define success as work+ family in a culture of gender. American Psychologist, 65(3), 182.

Cubillo, L., \& Brown, M. (2003). Women into educational leadership and management: International differences? Journal of Educational Administration, 41(3), 278-291.

Drury, M. (2010). You Gotta Be Determined to Get in There: Voices of Women Higher Education Technology Leaders. Journal of Women in Educational Leadership, 8(2), 59-80.

Ellison, K. (2006). The mommy brain: How motherhood makes us smarter. Basic Books.

Elmuti, D., Jia, H., \& Davis, H. H. (2009). Challenges women face in leadership positions and organizational effectiveness: An investigation.Volume 8, Number 2-Fall 2009, 167.

Hashim, J. (2008). Learning barriers in adopting ICT among selected working women in Malaysia. Gender in Management: An International Journal, 23(5), 317-336.

Ismail, M., \& Rasdi, R. M. (2007). Impact of networking on career development: Experience of high-flying women academics in Malaysia. Human Resource Development International, 10(2), 153-168.

Kwah, Z. S., Kow, W. L., Lee, C. X., Lee, K. E., \& Lim, C. K. (2012). Barriers to Malaysian women career progression (Doctoral dissertation, UTAR).

Le Renard, A. (2008). "Only for Women:" Women, the State, and Reform in Saudi Arabia. The Middle East Journal, 62(4), 610-629.

Luke, C. (2000). One step up, two down: Women in higher education management in South East Asia. In M. Tight (Ed.), Academic work and life: What it is to be an academic, and how this is changing (Vol. 1, pp. 285-305). Greenwich, Conn: JAl.

Madsen, S. R., Longman, K. A., \& Daniels, J. R. (2012). Women's Leadership Development in Higher Education Conclusion and Implications for HRD.Advances in Developing Human Resources, 14(1), 113-128.

Melamed, T. (1995). Barriers to women's career success: Human capital, career choices, structural determinants, or simply sex discrimination. Applied Psychology, 44(4), 295-314. 
Mooney, S., \& Ryan, I. (2009). A woman's place in hotel management: upstairs or downstairs?. Gender in Management: An International Journal, 24(3), 195-210.

Neale, J., \& Özkanlı, O. (2010). Organisational barriers for women in senior management: A comparison of Turkish and New Zealand universities. Gender and Education, 22(5), 547-563.

Nguyen, T. L. H. (2013). Barriers to and facilitators of female Deans' career advancement in higher education: an exploratory study in Vietnam. Higher Education, 66(1), 123-138.

Oakley, J. G. (2000). Gender-based barriers to senior management positions: Understanding the scarcity of female CEOs. Journal of business ethics, 27(4), 321-334.

Oplatka, I. (2006). Women in educational administration within developing countries: Towards a new international research agenda. Journal of Educational Administration, 44(6), 604-624.

Özkanlı, Ö., \& White, K. (2008). Leadership and strategic choices: Female professors in Australia and Turkey. Journal of Higher Education Policy and Management, 30(1), 53-63.

Parveen, M. (2014). Saudi Feminization: Dynamical phases of Saudi women in the field of Education and Employment.Journal of American Science 2014;10(1s).

Phendla, T. (2009). Women on the rise: Women navigating across social, political, eco nomic, and cultural arenas to claim their stake in educational leadership positions in South Africa. Women leading education across the continents, 57-64.

Sadi, M. A., \& Al-Ghazali, B. M. (2010). Doing business with impudence: A focus on women entrepreneurship in Saudi Arabia. African Journal of Business Management, 4(1), 1.

Shah, S. (2012). 'Contested Power! College heads in a Muslim society and leadership challenges' in C. Gerstl-Pepin and J. A. Aiken (eds). Social Justice Leadership for a global world, Chapter 4, pages 59-76.

Stead, V. \& Elliott, C.J. (2009). Women's leadership. Basingstoke: Palgrave Macmillan.

Still, L. V. (2006). Where are the women in leadership in Australia?. Women in Management Review, 21(3), 180-194.

Tomàs, M., Lavie, J. M., del Mar Duran, M., \& Guillamon, C. (2010). Women in academic administration at the university. Educational Management Administration \& Leadership, 38(4), 487-498.

Vinnicombe, S., \& Singh, V. (2011). Locks and keys to the boardroom. Gender in Management: An International Journal, 26(3), 200211.

Yin, R. (2003). Case study research: Design and methods. Sage Publications, Inc, 5, 11.

Yusof, A. M., Alias, R. A., \& Habil, H. (2012). Stereotyping in Graduate Education: An Insight of Women. Journal of e-Learning \& Higher Education, 2012, f1-9. 